\title{
Effect of a Debaryomyces hansenii and Lactobacillus buchneri Starter Culture on Aspergillus westerdijkiae Ochratoxin A Production and Growth during the Manufacture of Short Seasoned Dry-Cured Ham
}

\author{
Lucilla Iacumin, Martina Arnoldi 1 and Giuseppe Comi * \\ Department of Agricultural, Food, Environmental and Animal Science, University of Udine, Via Sondrio 2/a, \\ 33100 Udine, Italy; lucilla.iacumin@uniud.it (L.I.); arnoldi.martina@spes.uniud.it (M.A.) \\ * Correspondence: giuseppe.comi@uniud.it; Tel.: +39-0432-558129; Fax: +39-0432-558130
}

Received: 29 September 2020; Accepted: 19 October 2020; Published: 21 October 2020

\begin{abstract}
Recently, specific dry-cured hams have started to be produced in San Daniele and Parma areas. The ingredients are similar to protected denomination of origin (PDO) produced in San Daniele or Parma areas, and include pork leg, coming from pigs bred in the Italian peninsula, salt and spices. However, these specific new products cannot be marked as a PDO, either San Daniele or Parma dry cured ham, because they are seasoned for 6 months, and the mark PDO is given only to products seasoned over 13 months. Consequently, these products are called short-seasoned dry-cured ham (SSDCH) and are not branded PDO. During their seasoning period, particularly from the first drying until the end of the seasoning period, many molds, including Eurotium spp. and Penicillium spp., can grow on the surface and work together with other molds and tissue enzymes to produce a unique aroma. Both of these strains typically predominate over other molds. However, molds producing ochratoxins, such as Aspergillus ochraceus and Penicillium nordicum, can simultaneously grow and produce ochratoxin A (OTA). Consequently, these dry-cured hams may represent a potential health risk for consumers. Recently, Aspergillus westerdijkiae has been isolated from SSDCHs, which could represent a potential problem for consumers. Therefore, the aim of this study was to inhibit A. westerdijkiae using Debaryomyces hansenii or Lactobacillus buchneri or a mix of both microorganisms. Six $D$. hansenii and six L. buchneri strains were tested in vitro for their ability to inhibit A. westerdijkiae. The strains D. hansenii (DIAL) 1 and L. buchneri (Lb) 4 demonstrated the highest inhibitory activity and were selected for in situ tests. The strains were inoculated or co-inoculated on fresh pork legs for SSDCH production with OTA-producing A. westerdijkiae prior to the first drying and seasoning. At the end of seasoning (six months), OTA was not detected in the SSDCH treated with both microorganisms and their combination. Because both strains did not adversely affect the SSDCH odor or flavor, the combination of these strains are proposed for use as starters to inhibit OTA-producing A. westerdijkiae.
\end{abstract}

Keywords: D. hansenii; L. buchneri; A. westerdijkiae; biocontrol; ham

\section{Introduction}

Recently, a particular type of dry-cured ham has begun to be produced in different Italian areas. The product is obtained from pork legs (minimum $12 \mathrm{~kg}$ ) that are brined and seasoned for only six months. Because it is seasoned for less than 13 months, this product cannot be branded as a protected denomination of origin (PDO) product, such as San Daniele or Parma dry-cured hams. Indeed, they are called short-seasoned dry-cured ham (SSDCH), and their production process is presented in Table 1 . Maturation step is the production phase in which scheduled and controlled environmental conditions 
(temperature, humidity, and ventilation) and salt are used to dry fresh meat, allowing also all the enzymatic reactions to obtain the final product "prosciutto", which can be perfectly preserved without the use of additional preservatives. The uncovered surface of the thighs inner side is covered with salt ad libitum, and the salting phase lasts one day for each kilogram of thigh meat. Then the thighs are manually or mechanically pressed to facilitate the salt penetration and to drain even the last residues of blood from the meat. Subsequently, first and second drying, pre-seasoning, and seasoning are performed. The stability of the product depends on salt and dehydration/maturation process, in fact, lowering the water activity $(\mathrm{Aw})$ to $\leq 0.90[1,2]$ the microbial activity is inhibited. However, molds can develop spontaneously from the mycobiota of the production environment or by contamination with spices on the hams, particularly at the pre-seasoning and seasoning steps, when excessive humidity is present due to relative humidity (R.H.) control. In addition, molds grow when there are high levels of condensation on the surface of the hams, producing mycelia and spores that rapidly spread in the air and on the apparatuses of the pre-seasoning and seasoning areas. The indigenous mold mycobiota has beneficial seasoning effects, positively contribute to the unique characteristics of the final product [3]. Indeed, these molds prevent excessive drying of the surface, improve the texture, and limit excessive hardness of the flesh due to their proteolytic activities, and they also exert antioxidant effects, contribute to color production and improve the aroma and flavor [3-7]. The molds on the surface of dry-cured ham have been studied in great detail [3,4,7-15]. Penicillium spp., Aspergillus spp., and Eurotium spp. are the most common molds present during all stages of ham production [4]. The succession or the prevalence of specific genera strictly depends on the temperature at which seasoning is performed, the moisture of the meat, and the relative humidity $[1,14,16]$. However, inadequate processing procedures can increase the development of molds that can lead to negative effects, such as the production of mycotoxins (ochratoxin A) and off-flavors and off-odors. Nevertheless, in some cases, the use of short seasoning times can cause high moisture levels on the surface of the hams, which has detrimental effects, such as the growth of ochratoxin A (OTA)-producing molds. Several authors demonstrated the presence of OTA in meat products, due to the ability to grow on the surface of meat products of numerous fungi (Penicillium verrucosum, P. nordicum, Aspergillus ochraceus, and A. westerdijkiae) during seasoning and storage producing OTA $[1,13,17,18]$. Recently, small-scale or artisanal lots of SSDCH or meat products were contaminated with $A$. westerdijkiae $[16,19,20]$. This mold can grow during the drying and seasoning steps and produces over $1 \mu \mathrm{g}$ OTA kg${ }^{-1}$ meat. A. westerdijkiae is included in the Circumdati section and is considered a new species, differing from $A$. ochraceus because of the cream color of sclerotia, failed in growth at $37^{\circ} \mathrm{C}$ and greater OTA production [21-23]. With OTA being classified by the International Agency for Research of Cancer (IARC) as a "Group B" of carcinogenic molecules in humans [24], legal limits have been introduced for OTA concentration in foods (i.e., $1 \mu \mathrm{g} \mathrm{kg}^{-1}$ in meat and meat products, Italian Ministry of Health Circular no. 10-93 09/06/1999). Consequently, it is essential to advance in efficient strategies to eliminate the risk [18]. For food detoxification purposes, chemical, physical, and biological approaches have been used $[25,26]$, but they resulted in a failure to remove OTA due to its high stability [27]. Thus, an effective strategy remains to be developed that can limit or inhibit the growth of OTA-producing molds and the consequent OTA production. The most realistic and interesting method is the use of bioprotective cultures, which is based on the antagonistic activity of autochthonous yeast and LAB species against molds [26]. Several studies $[1,16,18,28-32]$ have evaluated the ability of autochthonous yeast to protect meat products against mold growth. In particular, D. hansenii and Candida famata were identified as the primary yeasts present in meat products from the early stage of seasoning to the end, when it becomes the predominant strain $[3,33-36]$. Consequently, D. hansenii is largely used as a starter culture in European sausages [33,37]. In addition, Saccharomycopsis fibuligera gives good results in limiting the growth and OTA production of P. nordicum and A. ochraceus in speck [1], despite it rarely being present in meat products [37]. Recently, we isolated various Lactobacillus buchneri strains in SSDCH surfaces without molds and hypothesized they could be used as bioprotective agents against OTA producing molds. Yeasts and LAB, due to their natural presence in meat products, were used as a first weapon 
for biocontrol against pathogenic microorganisms [29-31]. Concerning yeasts, their effectiveness in molds inhibition on meat products needs to be prudently evaluated [31,36], but the success of their usage on dry-cured ham [31] has been investigated and demonstrated both in vitro and in situ against OTA-producing molds $[16,29,30,38,39]$. However, these results should be improved upon, because it was recently demonstrated that some mold species such as $A$. westerdijkiae can produce more OTA than others such as A. ochraceus and P. nordicum. Considering that little is known about the bioprotective effects of LAB against molds and that the many opportunities that yeasts and LAB could have in mold inhibition, the goal of this study was to evaluate the abilities of Debaryomyces hansenii and Lactobacillus buchneri to control A. westerdijkiae OTA production during SSDCH production.

Table 1. Flowchart of dry cured ham production.

\begin{tabular}{lccc}
\hline Production Phases & Time & Temperature & R.H. \% \\
\hline Raw meat-Trimming & $24 \mathrm{~h}$ & $1-7^{\circ} \mathrm{C}$ & $50-60$ \\
Brining & 15 day & $1-4{ }^{\circ} \mathrm{C}$ & $75-88$ \\
Pressing & 2 day & $4{ }^{\circ} \mathrm{C}$ & $70-75$ \\
Rest & 50 days & $4-10^{\circ} \mathrm{C}$ & $70-75$ \\
Washing & $5 \mathrm{~h}$ & & \\
I Drying & 7 days & $20-21^{\circ} \mathrm{C}$ & 90 \\
II Drying/pre-seasoned & 20 day & $14-20^{\circ} \mathrm{C}$ & $70-85$ \\
Seasoning & 3 months & $15-22^{\circ} \mathrm{C}$ & $70-80$ \\
\hline
\end{tabular}

R.H.: Relative Humidity.

\section{Materials and Methods}

The microorganisms used in this study included 6 strains of Debaryomyces hansenii (DIAL1, DIAL2, DIAL3, DIAL4, DIAL5, and DIAL6), selected from 90 isolates from meat products, and 6 strains of L. buchneri, including two freeze-dried commercial L. buchneri strains (LABb2 and LABb3) and 4 selected from 40 isolates from SSDCH products (Lb1, Lb2, Lb3, and Lb4). Either the D. hansenii or L. buchneri strains were previous tested in vitro for their activity against $A$. ochraceus. All of the microorganisms were stored in the Collection of the Agricultural, Food, Environmental and Animal Science Department of the University of Udine (Udine, Italy). The twelve strains were selected for potential competition against $A$. westerdijkiae. The yeast strains were maintained in malt extract modified agar (MEMA, Oxoid, Italy) medium supplemented with dextrose (1\%) and peptone (1\%), and the LAB were cultured in MRS agar (De Man, Rogosa, Sharpe, Oxoid, Italy).

\subsection{Preparation of D. hansenii and L. buchneri Inocula}

The $D$. hansenii strains were grown on MEMA at $25^{\circ} \mathrm{C}$ for $48-72 \mathrm{~h}$. Suspensions were prepared by adding a loopful of cells to peptonized water $(0.7 \% \mathrm{NaCl}$ and $0.1 \%$ peptone in $1000 \mathrm{~mL}$ of water). The density of the yeast cultures was determined spectrophotometrically at an optical density at $600 \mathrm{~nm}\left(\mathrm{OD}_{600}\right)$ of 0.1 , after which serial dilutions were prepared to obtain the concentrations used for the experiments. The L. buchneri strains were maintained at $-80^{\circ} \mathrm{C}$ in vials with MRS broth $+30 \%$ (v/v) glycerol (Oxoid, Italia). The strains were grown in MRS broth (Oxoid, Italia) at $37^{\circ} \mathrm{C}$ for $24 \mathrm{~h}$. Then, the suspensions were standardized to an optical density at $600 \mathrm{~nm}\left(\mathrm{OD}_{600}\right)$ of 0.1 , and their microbial counts were evaluated. Specifically, serial dilutions were performed in peptonized water, and $0.1 \mathrm{~mL}$ of each dilution was spread onto MRS plates (Oxoid, Italy). The plates were incubated at $37^{\circ} \mathrm{C}$ for $48 \mathrm{~h}$, and the resulting colonies were counted. Each suspension contained approximately $7 \log \mathrm{CFU}$ (colony-forming unity) $\mathrm{mL}^{-1}$. A mixed suspension of both microorganisms was generated by mixing $5 \mathrm{~mL}$ of $7 \log$ D. hansenii $\mathrm{mL}^{-1}$ to $5 \mathrm{~mL}$ of $7 \log$ L. buchneri $\mathrm{mL}^{-1}$ to obtain a final suspension at $7 \log \mathrm{CFU} \mathrm{mL} \mathrm{m}^{-1}$. 


\subsection{Preparation of the Aspergillus westerdijkiae Inoculum}

The A. westerdijkiae strain used in this study was isolated from meat product and stored in the Collection of the Department of Food Science of the University of Udine (DIAL, Udine, Italy). The strain was maintained and grown on malt extract modified agar (Oxoid, Italy) supplemented with dextrose $(1 \%)$ and peptone $(1 \%)$ at $25^{\circ} \mathrm{C}$ for $5-7$ days. This specific strain was isolated from dry-cured ham $(\mathrm{DCH})$ in a previous study and identified at the molecular level (accession number, KY608057.1). The A. westerdijkiae strain was grown on Czapek yeast extract agar plates (Oxoid, Italy) incubated at $25^{\circ} \mathrm{C}$ for seven days. At the end of the incubation period, the conidia were removed from the culture surface according to the method reported by Virgili et al. [31] and suspended in peptonized water. Then, the conidial suspension was diluted to $10^{4}, 10^{6}$, and $10^{8}$ conidia $\mathrm{mL}^{-1}$ using a hemocytometer.

\subsection{Inhibition of A. westerdijkiae by D. hansenii and L. buchneri Strains}

The inhibition assay was performed using the method described by Virgili et al. [31] and Bleve et al. [40] and modified as follows: The experiments for D. hansenii were performed on MEMA adjusted to $\mathrm{pH} 6.0$ and for L. buchneri on MRS (Oxoid, Italy). Top agar overlays were prepared by mixing $D$. hansenii suspensions in $10 \mathrm{~mL}$ of MEMA broth with $0.7 \%$ agar and $1 \%, 3 \%$, and $5 \%$ $\mathrm{NaCl}$ (MEMA medium) and by mixing a L. buchneri suspensions in MRS broth with $0.7 \%$ agar, $0.3 \%$ yeast extract and $1 \%, 3 \%$, and $5 \% \mathrm{NaCl}$ added (MRSYE medium). Each of the top agars, containing different concentrations of $D$. hansenii or L. buchneri $\left(10^{2}, 10^{4}\right.$, or $\left.10^{6} \mathrm{CFU} \mathrm{mL} \mathrm{mL}^{-1}\right)$ prepared to investigate differences among different yeasts and LAB inocula, were transferred to Petri plates containing $15 \mathrm{~mL}$ of MEMA or MRS agar, respectively, resulting in a thick, continuous layer on the surface of the agars. Top agars without $D$. hansenii or L. buchneri were also spotted on MEMA and MRS as controls. Three $10 \mu \mathrm{L}$ aliquots of $A$. westerdijkiae harboring $10^{6}$ conidia $\mathrm{mL}^{-1}$ were spotted on each top agar. The level of the $A$. westerdijkiae concentration was chosen to consider the worst degree of contamination. Three replicate experiments were performed for each yeast and LAB strain. Mold growth was expressed as the average measurement $(\mathrm{mm})$ of two orthogonal diameters per colony after 14 days of incubation at $22{ }^{\circ} \mathrm{C}$. The inhibitory activity was calculated using the equation reported by Lima et al. [41]:

$$
\% \text { Inhibitory activity }=\frac{(\text { Mould grouth in control plate }- \text { Mould growth in treated plate })}{\text { Mould growth in control plate }} \times 100
$$

\subsection{Inhibitory Activity with Different Concentrations of D. hansenii and L. buchneri}

D. hansenii (DIAL1) and L. buchneri (Lb4), which demonstrated the best performance in the aforementioned tests, were used. The method according to Virgili et al. [31] was used with the following modifications, and the concentration of yeast and LAB in the top agar was altered. Briefly, top agars $(3 \% \mathrm{NaCl})$ containing different concentrations $\left(10^{2}, 10^{4}\right.$, or $\left.10^{6} \mathrm{CFU} \mathrm{mL}{ }^{-1}\right)$ of yeast, $\mathrm{LAB}$ and mixtures of both $(\mathrm{Dh} / \mathrm{Lb}$, at 1:1) ratio were used to examine the differences among yeasts and LAB at the different inocula concentrations. MRSYE medium was used to assess the activity of $\mathrm{Dh} / \mathrm{Lb}$. Ten milliliters of inoculated top agars were distributed onto $15 \mathrm{~mL}$ of MEMA or MRS medium, and three $10 \mu \mathrm{L}$ suspensions containing $10^{8}$ conidia $\mathrm{mL}^{-1}$ of the mold were then spotted separately onto each plate and incubated at $22{ }^{\circ} \mathrm{C}$ for 14 days. Moreover, in this case the level of the A. westerdijkiae concentration was chosen to consider the worst degree of contamination. Three replicate experiments were performed for each test. Top agar without D. hansenii and L. buchneri and $\mathrm{Dh} / \mathrm{Lb}$ inocula were also spotted as controls on MEMA, MRS, and MRSYE medium, respectively and inoculated by spots with $A$. westerdijkiae.

\subsection{Inhibitory Activity at Different Concentrations of A. westerdijkiae}

The abovementioned method [31] was used with the following modifications. The concentration of microorganisms in top agars $(3 \% \mathrm{NaCl})$ was $10^{6} \mathrm{CFU} \mathrm{mL}^{-1}$. D. hansenii DIAL1, L. buchneri Lb4, and $\mathrm{Dh} / \mathrm{Lb}$, which exhibited the best performance in the aforementioned test, were used. Ten milliliters 
of inoculated top agar were distributed onto $15 \mathrm{~mL}$ of MEMA or MRS. MRSYE medium was used to assess the activity of $\mathrm{Dh} / \mathrm{Lb}$. Three $10 \mu \mathrm{L}$ suspensions containing different concentrations of conidia $\left(10^{4}, 10^{6}\right.$, and $10^{8}$ conidia $\left.\mathrm{mL}^{-1}\right)$ of $A$. westerdijkiae were then separately spotted onto each plate and incubated at $22{ }^{\circ} \mathrm{C}$ for 14 days. Three replicate experiments were performed. Top agar without $D$. hansenii and $L b$. buchneri and $\mathrm{Dh} / \mathrm{Lb}$ inocula were also spotted as controls on MEMA, MRS, and MRSYE medium respectively and inoculated by spots with $A$. westerdijkiae.

\subsection{Inhibitory Activity of D. hansenii and L. buchneri and Dh/Lb on OTA Production in the Dry-Cured Ham Model System}

The Inhibitory Activity of D. hansenii and L. buchneri and $\mathrm{Dh} / \mathrm{Lb}$ on OTA Production in the Dry-Cured Ham Model System was performed using the method described by Battilani et al. [12], modified. Four SSDCH with different Aw values were collected from a San Daniele facility. From each SSDCH, samples (50 $\mathrm{mm}$ in diameter and $5 \mathrm{~mm}$ in height) were excised using a hollow metal sampler with a cylindrical cutting edge. The Aw values of the samples were measured with an AquaLab CX-2 instrument (Steroglass, Pullman, WA, USA) as $0.960 \pm 0.005,0.940 \pm 0.005,0.920 \pm 0.005$, and $0.900 \pm 0.005$. After being dipped in absolute ethanol for $2 \mathrm{~min}$, the samples were removed and flamed to sterilize them prior to inoculation [7]. Then, the samples were placed in Petri plates, inoculated, and placed in sealed boxes equipped with beakers containing $\mathrm{NaCl}$ solutions [42] with the same Aw values as the four SSDCH samples. The salt solutions were prepared with distilled water (w/v) at 6.57\% NaCl (Aw 0.96), 9.38\% NaCl (Aw 0.94), 11.90\% NaCl (Aw 0.92), and 14.18\% NaCl (Aw 0.90). Each Aw value was confirmed using the AquaLab CX-2 instrument. The samples were incubated at $20{ }^{\circ} \mathrm{C}$ for 30 days in the dark, because usually great part of the dry cured ham seasoning is preferably made in the dark to eliminate the risk of fat photooxidation. Four different inocula or co-inocula, spotted on each samples, were tested: (1) Control A. westerdijkiae $\left(10^{4}\right.$ conidia $\left.\mathrm{cm}^{-2}\right)$; (2) D. hansenii DIAL1 $\left(10^{6} \mathrm{CFU} \mathrm{g}^{-1}\right)$ versus A. westerdijkiae $\left(10^{4}\right.$ conidia $\left.\mathrm{cm}^{-2}\right)$; (3) L. buchneri Lb4 $\left(10^{6} \mathrm{CFU} \mathrm{g}^{-1}\right)$ versus A. westerdijkiae $\left(10^{4}\right.$ conidia $\left.\mathrm{cm}^{-2}\right)$; and (4) a mix of D. hansenii DIAL1 + L. buchneri Lb4 (1/1 ratio; $10^{6}$ CFU g $\left.{ }^{-1}\right)$ versus $A$. westerdijkiae $\left(10^{4}\right.$ conidia $\left.\mathrm{cm}^{-2}\right)$. Each condition was evaluated in triplicate. At the end of the incubation period, the 48 samples were collected and analyzed for OTA according to the method reported by Matrella et al. [17]. Briefly: $10 \mathrm{~g}$ sample was homogenized with $6 \mathrm{~mL}$ of $1 \mathrm{M}$ phosphoric acid using an UltraTurrax T25 homogenizer for a $5 \mathrm{~min}$. A $2.5 \mathrm{~g}$ aliquot of the homogenate was extracted with $5 \mathrm{~mL}$ of ethyl acetate and then centrifuged for $5 \mathrm{~min}$ at $4000 \mathrm{rpm}$. The organic phase was removed, re-extracted and reduced to approximately $3 \mathrm{~mL}$ and back-extracted with $3 \mathrm{~mL}$ of $0.5 \mathrm{M} \mathrm{NaHCO}_{3}, \mathrm{pH}$ 8.4. The aqueous extract was acidified to $\mathrm{pH}=2.5$ with $7 \mathrm{M} \mathrm{H}_{3} \mathrm{PO}_{4}$ and briefly sonicated to strip the $\mathrm{CO}_{2}$ formed. OTA was finally back extracted into $3 \mathrm{~mL}$ ethylacetate; the organic phase was evaporated to dryness under $\mathrm{N}_{2}$ stream, reconstituted in $150 \mu \mathrm{L}$ of mobile phase and a $20 \mu \mathrm{L}$ aliquot injected in the HPLC apparatus consisted of a Dionex P680 LPG pump. The fluorescence detector was a Varian mod. 9070; fluorescence excitation and emission wavelengths were 334 and $460 \mathrm{~nm}$, respectively.

\subsection{Inhibitory Activity of Yeasts towards OTA Production during Dry-Cured Ham Seasoning}

Sixteen fresh pork legs (FPLs) were collected. Each FPL (12 kg) was trimmed according to the traditional procedure and was then salted and treated until the period of first drying, at which time the FPLs were inoculated as follows. Four FPLs were inoculated, by spotting, with a suspension of $A$. westerdijkiae (final concentration of $10^{4}$ conidia/ $\mathrm{cm}^{2}$ ); 4 FPLs were inoculated with a mix of A. westerdijkiae and $D$. hansenii (final concentration $10^{4}$ conidia/ $10^{6} \mathrm{CFU} \mathrm{cm}^{-2}$ ); 4 FPLs were inoculated

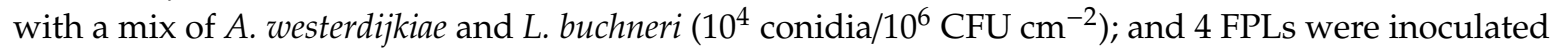

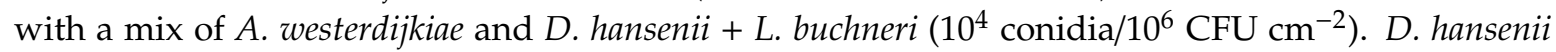
DIAL1 and L. buchneri Lb4 strains were used. All of the FPLs were seasoned for six months according to the traditional procedure of SSDCH (Table 1). At the end of the second drying and seasoning period, $100 \mathrm{~cm}^{2}$ samples were taken from a depth of $0.5 \mathrm{~cm}$ below the meat surface and analyzed for OTA 
and for D. hansenii, L. buchneri, and A. westerdijkiae growth. Briefly, meat collected from a depth of $0.5 \mathrm{~cm}$ below the surface was homogenized using a Stomacher instrument (Lab Blender 400, PBI, Milan, Italy), and $10 \mathrm{~g}$ of the homogenate was then used for the analysis. Additional $10 \mathrm{~g}$ were sampled and used to value D. hansenii, L. buchneri, and A. westerdijkiae growth. D. hansenii was counted in malt extract modified agar (Oxoid, Italy) medium supplemented with dextrose (1\%) and peptone (1\%) and tetracycline chloride $\left(10 \mathrm{mg} \mathrm{L}^{-1}\right.$; Sigma, Milan, Italy) incubated at $25^{\circ} \mathrm{C}$ for 3 days, the LAB in MRS agar (Oxoid, Italy) added with Delvocid (25 $\mathrm{mg} \mathrm{L}^{-1}$, DSM, Food Specialities, Leewuarden, the Netherlands) incubated at $37^{\circ} \mathrm{C}$ for $48-72 \mathrm{~h}$, and A. westerdijkiae in Czapek yeast extract agar plates (Oxoid, Italy) added with tetracycline chloride $\left(10 \mathrm{mg} \mathrm{L}^{-1}\right.$; Sigma, Italy) incubated at $25^{\circ} \mathrm{C}$ for seven days.

OTA was extracted and evaluated according to the method described by Matrella et al. [17]. Before sampling for OTA analysis, the surface of each SSDCH was also observed with a stereoscope (320X; WILD M 420, Heerbrugg, Switzerland) to assess the presence of mold growth (i.e., hyphae). In the case of presence of hyphae, they were isolated in MEMA and the grown colonies were identified comparing to the $A$. westerdijkiae ones.

\subsection{Sensorial Analysis}

To evaluate the influence of the yeast and LAB culture starter on the organoleptic characteristics of the product, a sensory analysis was performed using the triangle test methodology UNI EN ISO 10399, triangle test (2018). FPLs were divided into 4 lots. Before starting the first drying step, lot A (3 FPL) was inoculated with a suspension of D. hansenii DIAL1 $\left(10^{6} \mathrm{CFU} \mathrm{cm}^{-2}\right)$, lot B (3 FPL) was inoculated with L. buchneri Lb4 $\left(10^{6} \mathrm{CFU} \mathrm{cm}^{-2}\right)$, lot C (3 FPL) was inoculated with $\mathrm{Dh} / \mathrm{Lb}$, and lot D (3 FPL) was not inoculated with either culture and represents the control. All FPLs were seasoned according to the traditional procedure (Table 1). At the end of the seasoning period (6 months), all the lots were subjected to the triangle test to compare their quality. Twenty non-professional assessors were presented with three products, two of which were identical. Non-professional assessors were chosen, because they represent the typical consumers, and were asked to state which product they believed was a unique sample. The assessors who indicated the presence of two distinct samples were presented the four different lots and asked to identify the best sample, considering the follow parameters compact and homogeneous slices; ruby red color; whitish fat; compact and not elastic consistency; delicate and distinctive bouquet; delicate taste; and no spices flavors perception.

\subsection{Statistical Analysis}

The values of the various parameters were compared through one-way analysis of variance. The averages were compared with Tukey's honest significance test using the Statistical Graphics software package (STSC, Inc. Rockville, MD, USA).

\section{Results}

Different inhibitory activities against $A$. westerdijkiae were observed among the tested strains in vitro $(p<0.05)$. D. hansenii DIAL1 and L. buchneri Lb4 showed the highest inhibitory activities against A. westerdijkiae for all the tested media and $\mathrm{NaCl}$ concentrations (Tables 2 and 3). The diameters of A. westerdijkiae colonies were reduced by approximately $75 \%, 70 \%$, and $72 \%$ by D. hansenii DIAL1 and by approximately $38.2 \%, 35.5 \%$, and $25.5 \%$ by L. buchneri $\mathrm{Lb} 4$ in medium containing $1 \%, 3 \%$, and $5 \% \mathrm{NaCl}$, respectively. Based on these results, both strains were selected to further assess their inhibitory effects in vitro and in situ. Different concentrations of both D. hansenii DIAL1 and L. buchneri Lb4 strains were tested separately and in combination to evaluate their activities against A. westerdijkiae. As expected, the inhibitory activity was dependent on both the tested strains. Indeed, in vitro concentrations of approximately $10^{6} \mathrm{CFU} \mathrm{mL} \mathrm{m}^{-1}$ of $D$. hansenii and L. buchneri showed a high inhibitory effect $(p<0.05$; Table 4). 
Table 2. Percentage of inhibitory activity of Debaryomyces hansenii vs A. westerdijkiae co-inoculated in agar plates.

\begin{tabular}{cccc}
\hline \multirow{2}{*}{ Starter Yeast } & \multicolumn{3}{c}{$\%$ Inhibitory on A. westerdijkiae } \\
\cline { 2 - 4 } & $\mathbf{1 \%} \mathbf{~ N a C l}$ & $\mathbf{3 \% ~ N a C l}$ & $\mathbf{5 \% ~ N a C l}$ \\
\hline D. hansenii DIAL1 & $75.0 \pm 0.5 \mathrm{a}$ & $70.0 \pm 0.3 \mathrm{a}$ & $72.0 \pm 0.1 \mathrm{a}$ \\
\hline D. hansenii DIAL2 & $68.3 \pm 0.2 \mathrm{~b}$ & $67.2 \pm 0.8 \mathrm{~b}$ & $70.2 \pm 0.3 \mathrm{~b}$ \\
\hline D. hansenii DIAL3 & $70.3 \pm 0.5 \mathrm{~b}$ & $68.5 \pm 0.2 \mathrm{c}$ & $68.3 \pm 0.3 \mathrm{c}$ \\
\hline D. hansenii DIAL4 & $70.0 \pm 0.2 \mathrm{~b}$ & $69.3 \pm 0.2 \mathrm{c}$ & $69.3 \pm 0.7 \mathrm{c}$ \\
\hline D. hansenii DIAL5 & $68.5 \pm 0.2 \mathrm{~b}$ & $69.0 \pm 0.2 \mathrm{c}$ & $68.0 \pm 0.3 \mathrm{c}$ \\
\hline D. hansenii DIAL6 & $70.3 \pm 0.5 \mathrm{~b}$ & $69.3 \pm 0.2 \mathrm{c}$ & $66.5 \pm 0.3 \mathrm{~d}$
\end{tabular}

Data represent the means \pm standard deviations of the total samples; mean with the same letters within the same column (following the values) are not significantly differently $(p<0.05)$.

Table 3. Percentage of inhibitory activity of Lactobacillus buchneri vs A. westerdijkiae co-inoculated in agar plates.

\begin{tabular}{cccc}
\hline \multirow{2}{*}{ Starter LAB } & \multicolumn{3}{c}{$\%$ Inhibitory on A. westerdijkiae } \\
\cline { 2 - 4 } & $\mathbf{1 \%} \mathbf{~ N a C l}$ & $\mathbf{3 \% ~ N a C l}$ & $\mathbf{5 \%} \mathbf{N a C l}$ \\
\hline L. buchneri $\mathrm{LABb} 2$ & $20.0 \pm 0.2 \mathrm{c}$ & $15.0 \pm 0.2 \mathrm{c}$ & $10.0 \pm 0.3 \mathrm{~b}$ \\
\hline L. buchneri $\mathrm{LABb} 3$ & $23.0 \pm 0.3 \mathrm{~b}$ & $17.0 \pm 0.3 \mathrm{~b}$ & $12.0 \pm 0.5 \mathrm{c}$ \\
\hline L. buchneri $\mathrm{Lb} 1$ & $16.5 \pm 0.3 \mathrm{a}$ & $11.3 \pm 0.5 \mathrm{a}$ & $9.5 \pm 0.2 \mathrm{a}$ \\
\hline L. buchneri $\mathrm{Lb} 2$ & $22.3 \pm 0.3 \mathrm{~b}$ & $18.2 \pm 0.5 \mathrm{~d}$ & $12.2 \pm 0.5 \mathrm{c}$ \\
\hline L. buchneri $\mathrm{Lb3}$ & $24.0 \pm 0.5 \mathrm{~d}$ & $21.3 \pm 0.4 \mathrm{e}$ & $18.5 \pm 0.2 \mathrm{~d}$ \\
\hline L. buchneri $\mathrm{Lb} 4$ & $38.2 \pm 0.2 \mathrm{e}$ & $35.5 \pm 0.4 \mathrm{f}$ & $25.5 \pm 0.2 \mathrm{e}$ \\
\hline
\end{tabular}

Data represent the means \pm standard deviations of the total samples; mean with the same letters within the same column (following the values) are not significantly differently $(p<0.05)$.

Table 4. Percentage of inhibitory effect of different concentration of D. hansenii and L. buchneri vs A. westerdijkiae co-inoculated in agar plates.

\begin{tabular}{|c|c|}
\hline Microorganisms & Inhibitory Effect on $A$. westerdijkiae \\
\hline \multicolumn{2}{|l|}{ D. hansenii DIAL1 } \\
\hline $10^{2} \mathrm{CFU} \mathrm{mL}^{-1}$ & $31.0 \pm 0.2 \mathrm{a}$ \\
\hline $10^{4} \mathrm{CFU} \mathrm{mL}^{-1}$ & $50.4 \pm 0.3 b$ \\
\hline $10^{6} \mathrm{CFU} \mathrm{mL}^{-1}$ & $74.8 \pm 0.4 \mathrm{c}$ \\
\hline \multicolumn{2}{|l|}{ L. buchneri Lb4 } \\
\hline $10^{2} \mathrm{CFU} \mathrm{mL}-1$ & $19.0 \pm 0.4 \mathrm{a}$ \\
\hline $10^{4} \mathrm{CFU} \mathrm{mL}^{-1}$ & $21.2 \pm 0.3 b$ \\
\hline $10^{6} \mathrm{CFU} \mathrm{mL}^{-1}$ & $38.2 \pm 0.2 \mathrm{c}$ \\
\hline \multicolumn{2}{|l|}{$\mathrm{Dh} / \mathrm{Lb}$} \\
\hline $10^{2} \mathrm{CFU} \mathrm{mL} \mathrm{L}^{-1}$ & $43.5 \pm 0.5 \mathrm{a}$ \\
\hline $10^{4} \mathrm{CFU} \mathrm{mL}^{-1}$ & $68.0 \pm 0.4 b$ \\
\hline $10^{6} \mathrm{CFU} \mathrm{mL}^{-1}$ & $95.0 \pm 0.1 c$ \\
\hline
\end{tabular}

Data represent the means \pm standard deviations of the total samples; mean with the same letters within the

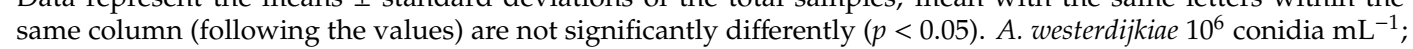
n.d.: Not done. Dh/L. buchneri (Lb): Mix D. hansenii and L. buchneri.

The antagonistic activities of $D$. hansenii and L. buchneri and $\mathrm{Dh} / \mathrm{Lb}\left(10^{6} \mathrm{CFU} \mathrm{mL}{ }^{-1}\right)$ were evaluated separately against different concentrations of $A$. westerdijkiae $\left(10^{2}, 10^{4}\right.$, and $10^{6}$ conidia $\left.\mathrm{mL}^{-1}\right)$. The percentage of inhibition varied according to the mold concentration (Table 5), with the lowest inhibition observed after inoculation with the highest mold concentration $(p<0.05)$. The activity 
of $D$. hansenii alone was higher than that of L. buchneri but lower than the ones of $\mathrm{Dh} / \mathrm{Lb}$. At $10^{6} \mathrm{CFU} \mathrm{mL} \mathrm{mL}^{-1}, \mathrm{Dh} / \mathrm{Lb}$ completely inhibited $A$. westerdijkiae at $10^{2}$ and $10^{4}$ conidia $\mathrm{mL}^{-1}$ (data not shown), which was not observed when the same concentrations of $D$. hansenii and L. buchneri were used. These results demonstrated that the inhibitory activity of $\mathrm{Dh} / \mathrm{Lb}$ was higher than that of $D$. hansenii and L. buchneri alone.

Table 5. Percentage of inhibitory effect of D. hansenii and L. buchneri vs different concentration of A. westerdijkiae co-inoculated in agar plates.

\begin{tabular}{cccc}
\hline \multirow{2}{*}{ A. westerdijkiae } & \multicolumn{3}{c}{ Inhibitory Effect of } \\
\cline { 2 - 4 } & D. hansenii & L. buchneri & Dh/Lb \\
\hline $10^{2} \mathrm{CFU} \mathrm{mL}^{-1}$ & $65.0 \pm 0.3 \mathrm{a}$ & $38.0 \pm 0.6 \mathrm{a}$ & $75.0 \pm 0.2 \mathrm{a}$ \\
\hline $10^{4} \mathrm{CFU} \mathrm{mL}^{-1}$ & $58.4 \pm 0.7 \mathrm{~b}$ & $30.2 \pm 0.3 \mathrm{~b}$ & $66.5 \pm 0.2 \mathrm{~b}$ \\
\hline $10^{6} \mathrm{CFU} \mathrm{mL}^{-1}$ & $45.0 \pm 0.5 \mathrm{c}$ & $8.0 \pm 0.5 \mathrm{c}$ & $55.0 \pm 0.3 \mathrm{c}$ \\
\hline
\end{tabular}

Data represent the means \pm standard deviations of the total samples; mean with the same letters within the same column (following the values) are not significantly differently $(p<0.05)$. Dh/Lb: Mix D. hansenii and L. buchneri; D. hansenii, L. buchneri, and Dh/Lb. concentration: $10^{4} \mathrm{CFU} \mathrm{mL}^{-1}$.

A reduction in mold growth limited OTA production as observed in SSDCH model systems. Table 6 displays the effects of D. hansenii, L. buchneri, and $\mathrm{Dh} / \mathrm{Lb}$ on OTA production by A. westerdijkiae in SSDCH slices with different Aw levels. The results showed that the SSDCH samples inoculated with either strain alone or with $\mathrm{Dh} / \mathrm{Lb}$ contained lower OTA concentrations than those inoculated with $A$. westerdijkiae alone $(p<0.05)$. Indeed, the OTA concentration in the SSDCH co-inoculated with $D$. hansenii and A. westerdijkiae was less than $2 \mu \mathrm{g} \mathrm{kg}^{-1}$ (Table 6). L. buchneri was less effective than $D$. hansenii and permitted $A$. westerdijkiae growth, which produced an OTA concentration over $10 \mu \mathrm{g} \mathrm{kg}^{-1}$. In contrast, OTA concentrations of $0.2-0.4 \mu \mathrm{g} \mathrm{kg}^{-1}$ were observed in SSDCH inoculated with $\mathrm{mD} / \mathrm{L}$, which is less than the limit $\left(1 \mu \mathrm{g} \mathrm{kg}^{-1}\right)$ allowed in meat and meat products by the Italian Ministry of Health (Circular no. 10-93 09/06/1999). As expected, slices of SSDCH with the higher Aw values (i.e., 0.96 and 0.94 ) exhibited the highest OTA concentrations (Table 6).

Table 6. Mean production of Ochratoxin A by A. westerdijkiae in control and selected D. hansenii and L. buchneri co-inoculated in dry cured ham model system with different water activity (Aw).

\begin{tabular}{ccccc}
\hline \multicolumn{5}{c}{ Ochratoxin A $\left(\mu \mathrm{g} \mathrm{kg}^{-1}\right)$ in Dry-Cured Ham Model } \\
\hline Aw & $\begin{array}{c}\text { A. westerdijkiae } \\
\text { Control }\end{array}$ & $\begin{array}{c}\text { A. westerdijkiae } \\
\text { vs. } \text { D. hansenii }\end{array}$ & $\begin{array}{c}\text { A. westerdijkiae } \\
\text { vs. } \text { L. buchneri }\end{array}$ & $\begin{array}{c}\text { A. westerdijkiae } \\
\text { vs. Dh/Lb }\end{array}$ \\
\hline 0.96 & $15.5 \pm 0.2 \mathrm{a}$ & $1.9 \pm 0.2 \mathrm{~b}$ & $13.0 \pm 0.4 \mathrm{c}$ & $0.2 \pm 0.1 \mathrm{~d}$ \\
\hline 0.94 & $12.3 \pm 0.3 \mathrm{a}$ & $1.8 \pm 0.2 \mathrm{~b}$ & $11.7 \pm 0.3 \mathrm{c}$ & $0.4 \pm 0.2 \mathrm{~d}$ \\
\hline 0.92 & $8.5 \pm 0.2 \mathrm{a}$ & $1.7 \pm 0.1 \mathrm{~b}$ & $6.4 \pm 0.2 \mathrm{c}$ & $0.3 \pm 0.1 \mathrm{~d}$ \\
\hline 0.90 & $6.0 \pm 0.5 \mathrm{a}$ & $1.5 \pm 0.2 \mathrm{~b}$ & $4.3 \pm 0.4 \mathrm{c}$ & $0.3 \pm 0.1 \mathrm{~d}$ \\
\hline
\end{tabular}

Data represent the means \pm standard deviations of the total samples; mean with the same letters within the same lines (following the values) are not significantly differently $(p<0.05)$. Dh/Lb mix D. hansenii and L. buchneri; $D$. hansenii, L. buchneri, and $\mathrm{Dh} / \mathrm{Lb}$. concentration: $10^{6} \mathrm{CFU} \mathrm{cm}{ }^{-2} ;$ A. westerdijkiae $10^{4}$ conidia cm$^{-2}$.

The inhibitory activity of both microorganisms or of $\mathrm{Dh} / \mathrm{Lb}$ against OTA-producing A. westerdijkiae during SSDCH production was assessed in situ (Table 7). Both microorganisms were co-inoculated separately or together $(\mathrm{Dh} / \mathrm{Lb})$ in FPLs with the A. westerdijkiae strain. All the inocula, were added at the beginning of the first drying phase. D. hansenii and L. buchneri grew till the end of the second drying phase, reaching $8.3 \pm 1.2$ and $6.8 \pm 1.1 \log \mathrm{CFU} \mathrm{cm}{ }^{-2}$, respectively $(p<0.05)$. Additionally, the mix culture $\mathrm{Dh} / \mathrm{Lb}$ grew, reaching $7.5 \pm 0.8$ and $6.5 \pm 0.2 \log \mathrm{CFU} \mathrm{cm}{ }^{-2}$, respectively (Table 7). Then during the seasoning phase, the concentration of both the microorganisms decreased due to the Aw, which reached the value of 0.91 . In particular the decrease for both the strains was between 0.3 and $0.5 \log \mathrm{CFU} \mathrm{cm}{ }^{-2}$. D. hansenii and the mix culture $\mathrm{Dh} / \mathrm{Lb}$ blocked the growth of A. westerdijkiae, 
and its concentration remains at level of the inoculum $\left(4.0 \log \mathrm{CFU} \mathrm{cm}{ }^{-2}\right)$ and, consequently $(p<0.05)$, the concentration of OTA was at level of $1.0 \pm 0.3$ and $<1.0 \mu \mathrm{g} \mathrm{kg}^{-1}$, respectively (Table 7). In addition, also A. westerdijkiae, grew till the end of the seasoning phase, when inoculated alone or with L. buchneri, reaching 7.2 and $5.2 \log \mathrm{CFU} \mathrm{cm}{ }^{-2}(p<0.05)$. The growth is also confirmed by the presence of OTA and by the presence of abundant hyphae on the FPLs, counted and identified in Czapek agar just as A. westerdijkiae. However, L. buchneri reduced the activity of $A$. westerdijkiae, which reached values about $4.8 \log \mathrm{CFU} \mathrm{cm}{ }^{-2}$ at the end of the second drying phase and $5.2 \log \mathrm{CFU} \mathrm{cm}{ }^{-2}$ at the end of seasoning phase, and consequently the values of OTA were at level of $5.5 \pm 0.8 \mu \mathrm{g} \mathrm{kg}^{-1}$ and $13.2 \pm 0.7 \mu \mathrm{g} \mathrm{kg}^{-1}$, respectively. Vice versa in samples where $A$. westerdijkiae was alone inoculated, its concentration reached values about $6.2 \log \mathrm{CFU} \mathrm{cm} \mathrm{cm}^{-2}$ at the end of the second drying phase and $7.2 \log \mathrm{CFU} \mathrm{cm}{ }^{-2}$, at the end of seasoning phase, presenting OTA values at level of $58.5 \pm 4.5 \mu \mathrm{g} \mathrm{kg}^{-1}$ and $110.5 \pm 0.6 \mu \mathrm{g} \mathrm{kg}^{-1}$, respectively (Table 7).

Table 7. Mean production of Ochratoxin A by A. westerdijkiae in control and selected D. hansenii and L. buchneri co-inoculated at the end of second drying and seasoning stages and their fate during the seasoning of short seasoning dry cured ham.

\begin{tabular}{|c|c|c|c|c|c|}
\hline & \multirow{2}{*}{ Phase } & OTA & D. hansenii & L. buchneri & A. westerdijkiae \\
\hline & & $\left(\mathrm{mg} \mathrm{kg}^{-1}\right)$ & \multicolumn{3}{|c|}{$\left(\mathrm{CFU} \mathrm{cm} \mathrm{cm}^{-2}\right)$} \\
\hline $\begin{array}{l}\text { End II } \\
\text { drying }\end{array}$ & $\begin{array}{c}\text { A. westerdijkiae vs. } \\
\text { D. hansenii } \\
\text { L. buchneri } \\
\text { Dh/Lb } \\
\text { A. westerdijkiae }\end{array}$ & $\begin{array}{c}<1.0 \mathrm{a} \\
5.5 \pm 0.8 \mathrm{~b} \\
<0.1 \mathrm{c} \\
58.5 \pm 4.5 \mathrm{~d}\end{array}$ & $\begin{array}{c}8.3 \pm 1.2 \mathrm{a} \\
\text { n.i. } \\
7.5 \pm 0.8 \mathrm{a} \\
\text { n.i }\end{array}$ & $\begin{array}{c}\text { n.i. } \\
6.8 \pm 1.1 \mathrm{a} \\
6.5 \pm 0.2 \mathrm{a} \\
\text { n.i }\end{array}$ & $\begin{array}{l}4.0 \pm 0.1 \mathrm{a} \\
4.8 \pm 0.8 \mathrm{~b} \\
4.0 \pm 0.3 \mathrm{a} \\
6.2 \pm 1.2 \mathrm{c}\end{array}$ \\
\hline $\begin{array}{c}\text { End } \\
\text { seasoning }\end{array}$ & $\begin{array}{l}\text { A. westerdijkiae vs } \\
\text { D. hansenii } \\
\text { L. buchneri } \\
\text { Dh/Lb } \\
\text { A. westerdijkiae }\end{array}$ & $\begin{array}{c}1.0 \pm 0.3 \mathrm{a} \\
13.2 \pm 0.7 \mathrm{~b} \\
<0.1 \mathrm{c} \\
110.5 \pm 0.6 \mathrm{~d}\end{array}$ & $\begin{array}{c}8.0 \pm 0.5 \mathrm{a} \\
\text { n.i } \\
7.0 \pm 0.3 \mathrm{~b} \\
\text { n.i. }\end{array}$ & $\begin{array}{c}\text { n.i. } \\
6.0 \pm 0.2 \mathrm{a} \\
5.9 \pm 0.5 \mathrm{a} \\
\text { n.i. }\end{array}$ & $\begin{array}{l}4.0 \pm 0.1 \mathrm{a} \\
5.2 \pm 0.8 \mathrm{~b} \\
4.0 \pm 0.3 \mathrm{a} \\
7.2 \pm 0.8 \mathrm{c}\end{array}$ \\
\hline
\end{tabular}

Data: OTA mean \pm standard deviations of 20 replicates: $\mu \mathrm{g} \mathrm{kg}^{-1}$; $\mathrm{LOD}<0.1 \mu \mathrm{g} \mathrm{kg}{ }^{-1}$; samples taken from a depth of $0.5 \mathrm{~cm}$ below the surface; Dh/Lb: Mix D. hansenii and L. buchneri. D. hansenii, L. buchneri, and Dh/Lb concentration: $10^{6} \mathrm{CFU} \mathrm{cm}{ }^{-2} ;$ A westerdijkiae $10^{4}$ conidia $\mathrm{cm}^{-2}$. n.i: Not inoculated. Data represent the means \pm standard deviations of the total samples; inside the end second ripening and the end seasoning, mean with the same letters within the same columns (following the values) are not significantly differently $(p<0.05)$.

Therefore, the data demonstrated that the $\mathrm{Dh} / \mathrm{Lb}$ inoculum was able to reduce or completely inhibit the growth $A$. westerdijkiae, both in vitro and in situ. Based on these promising results, the use of starter cultures of D. hansenii and of mix of D. hansenii and L. buchneri to control OTA-producing molds may be recommended, considering that they could permit to respect the limit proposed by the Italian Ministry of Health (Circular no. 10-93 09/06/1999).

However, before using both strains in the starter, it needed to evaluate their influence on the sensorial acceptability of the product. At the end of seasoning period (Table 1), SSDCH samples underwent a triangular test by a panel of 20 non-professional assessors. The results demonstrated the acceptability of the SSDCH supplemented with the starter cultures and no difference among lots A, B, $\mathrm{C}$ (with bio-protective cultures), and $\mathrm{D}$ (without protective cultures) were perceived (Table 8 ).

Table 8. Sensorial evaluation by not trained panelists.

\begin{tabular}{lcc}
\hline Lot of Production & Difference & Final Values Scores * \\
\hline Lot A vs. Lot B & $-20 / 20$ & $2 / 2$ \\
Lot A vs. Lot C & $-20 / 20$ & $2 / 2$ \\
Lot A vs. Lot D & $-20 / 20$ & $2 / 2$ \\
Lot B vs. Lot C & $-20 / 20$ & $2 / 2$ \\
Lot B vs. Lot D & $-20 / 20$ & $2 / 2$ \\
\hline
\end{tabular}

-: No difference; lot A (3 FPL) was inoculated with a suspension of D. hansenii DIAL1 $\left(10^{6} \mathrm{CFU} \mathrm{cm}{ }^{-2}\right)$, lot B (3 FPL) was inoculated with L. buchneri Lb4 $\left(10^{6} \mathrm{CFU} \mathrm{cm}{ }^{-2}\right)$, and lot C (3 FPL) was inoculated with Dh/Lb and lot D (3 FPL) was not inoculated with either culture and represents the control. * Scores (Lot vs Lot) 1 (excellent), 2 (good), 3 (sufficient), and 4 (poor). 
At sight, all the SSDCH slices, either inoculated or uninoculated, appeared compact and homogeneous. The color of the lean part was ruby red, whereas the fat part looked perfectly white, without any trace of oxidation (yellowish). Texture was compact, not elastic or chewy, the aromatic bouquet was mild and distinctive, as well as the taste was delicate, without any perception of spices or negative off-flavors.

\section{Discussion}

The goal of this study was to evaluate the effect of the two selected microorganisms on the growth and OTA production of $A$. westerdijkiae. To this end, six selected meat product-native yeast and six LAB starter strains, four of which were isolated from meat products and two were from commercial starter cultures, were separately inoculated or co-inoculated with OTA-producing mold either in vitro or in situ. The strains of Debaryomyces hansenii and Lactobacillus buchneri were selected because they are widespread on meat and meat products [33,43,44] and are considered safe by the food industry [25]. SSDCHs are typical meat products of San Daniele and Parma areas of Italy. They are produced by the same pork raw meat, salt and process technology of San Daniele or Parma dry-cured ham, except for the seasoning time, which is shorter. Indeed, SSDCHs are seasoned for 6 months, while PDO products over 13 month and consequently they cannot acquire the brand PDO. During the drying and seasoning process, a large population of microorganisms (primarily molds and yeasts) develops on the outer layers of dry-cured hams [1,3,7-13]. Some of these molds can produce OTA, such as $P$. nordicum, A. ochraceus, and A. westerdijkiae. Under some environmental conditions, such as high R.H., these molds can grow and synthesize OTA, which can represent a real risk towards human health. Various studies have determined OTA levels in different meats and meat products contaminated by ochratoxigenic molds $[1,7,12,13,45,46]$. Different methods can be used to inhibit OTA-producing molds $[1,13,47]$, the most common of which consists of spreading starter cultures on the meat product surface during the late drying and seasoning stages [1,28-31,36,47]. Mold, yeast and LAB starters are usually used in meat and food products because they limit the growth of pathogenic microorganisms by competing for nutrients and space and producing hydrolytic enzymes and toxins, and they also improve the sensorial quality of the product by secreting volatile compounds [1,36,48-54]. For yeasts and molds, the inhibitory mechanism is not fully understood, but it has been suggested that yeasts restrict nutrient availability and colonization sites, limiting the growth of OTA-producing molds [26]. However, it seems that the expression of non-ribosomal peptide synthetase gene linked to the OTA biosynthetic pathway of $P$. verrucosum is inhibited in presence of $D$. hansenii [32]. The present study was focused on assessing the use of D. hansenii and L. buchneri strains, both in vitro and in situ, against the OTA producer A. westerdijkiae. Under in vitro conditions, six D. hansenii and six L. buchneri strains significantly inhibited $A$. westerdijkiae growth. In particular D. hansenii DIAL1 and L. buchneri Lb4 showed the highest efficiencies on solid media. The inhibitory effect of $D$. hansenii DIAL1 was higher compared with that observed for L. buchneri Lb4 in all the in vitro tests, regardless to the salt concentration and the level of the D. hansenii, L. buchneri, and A. westerdijkiae inoculum. However, the inhibitory effects of $\mathrm{Dh} / \mathrm{Lb}$ mix were higher than those obtained using the separately inoculated strains. The inhibitory activity of $D$. hansenii strains against $P$. nordicum and $A$. ochraceus is well known [1,31]. Recently, Iacumin et al. [1] demonstrated a high inhibition activity of $D$. hansenii vs $P$. nordicum; higher than the inhibitory effect of $D$. hansenii vs $A$. westerdijkiae.

In particular, different strains of $D$. hansenii, Candida famata, Saccharomycopsis fibuligera, Candida zeylanoides, and Hyphopichia burtonii have been selected for their ability to grow in dry-cured ham-like substrates and have been shown to be highly effective against P. nordicum and A. ochraceus. Indeed, the inhibitory effect was observed at the strain level [1,29]. The results obtained using the D. hansenii strain assayed in this study confirmed the previous data from above studies. In vitro, the efficiency depends on the strain, the medium and the Aw value and on the lysed yeast cells, which may provide nutrients for P. nordicum, A. ochraceus, or A. westerdijkiae growth [1,29]. The inhibitory effects could be due to compounds and antimycotic compounds produced by yeast and LAB strains $[1,29,49,55]$ and 
mostly to the competition for nutrients $[1,36,38,56]$. Due to the large variability in OTA-producing molds on dry-cured ham and meat products $[1,20,31,34,36,57]$, yeasts and LAB inoculated at low concentrations were shown to be associated with low levels of mold inhibition [1]. In this study, the use of different yeast and LAB concentrations in vitro resulted in different $A$. westerdijkiae inhibitory effects, demonstrating that mold inhibition could depend on the competition for nutrients and on antimycotic factor production. Consequently, the highest yeast and LAB concentration $\left(10^{6} \mathrm{CFU} \mathrm{g}{ }^{-1}\right)$ assayed induced the largest inhibitory effect against the OTA-producing molds. Indeed, it was observed that the lower inoculum of protective culture produced either smaller quantities of antimould compounds or less competition for nutrients, and, consequently, the inhibition of $A$. westerdijkiae has been lower. The results confirmed the potential biocontrol effect of both yeast and LAB strains used in this study. Our data agree with the results reported by Virgili et al. [31] and Metfah et al. [36]. Furthermore, the inhibitory activity of the yeast and LAB was affected by the mold concentration. Virgili et al. [31] hypothesized that the concentration of OTA-producing molds in meat products is a key factor for the effectiveness of yeast starters. The use of LAB and a mix of yeast and LAB starter must be considered and evaluated. In this study, the use of bioprotective agents, including a mix of LAB and yeast, produced the best results in reducing the growth or OTA production of A. westerdijkiae. Furthermore, in the SSDCH model system, the data demonstrated the potential for the effective biocontrol of the OTA-producing A. westerdijkiae strain by D. hansenii DIAL1 and L. buchneri Lb4. The results appear to be strictly dependent on the Aw value and the bioprotective strains added separately or in combination. The reduced OTA concentration in the SSDCH model system with different Aw values compared with that observed in the control samples was rather notable. The antagonistic activities of $D$. hansenii and $L$. buchneri were also dependent on the Aw value and were different from the data reported by Simoncini et al. [30], who demonstrated that the variability in the antagonistic effect was affected by the strains of the different species used (D. hansenii and C. zeylanoides). In our study, the Aw value probably influenced either the bioprotective strains or $A$. westerdijkiae growth, as demonstrated by the control plate results, where the bioprotective strains were not added and the decreasing OTA concentration was correlated to the decrease in the Aw value. Moreover, in the SSDCH model system the OTA-reducing effects of $D$. hansenii were higher than those of L. buchneri, but the greatest effects were observed using a mix of both bioprotective strains. The bioprotective strains, alone or in combination, had positive effects on the inhibition of mold growth and OTA production and accumulation. The level of OTA presence in SDDCH was not always correlated to the level of $A$. westerdijkiae concentration. Indeed, no association was observed between the presence of mycotoxin and the biomass of the A. westerdijkiae OTA-producing strain, confirming the results of $\mathrm{Xu}$ et al. [58], who demonstrated that the production and concentration of some mycotoxins in food are not necessarily proportional to the biomass of the OTA-producing mold. Again, the data confirmed the biocontrol activity of $D$. hansenii against OTA-producing mold in meat products as previously demonstrated by various authors $[1,26,29,31,52]$. However, there are no data on the biocontrol activity of L. buchneri against OTA-producing molds, even though various LAB species isolated from different raw and processed foods can inhibit either the growth of mycotoxigenic molds or reduce the presence of mycotoxins $[30,31,40,56]$. Thus, this study provides the first demonstration of the use of an L. buchneri strain for the biocontrol of OTA-producing mold. OTA was only detected at high levels ( $58.5 \pm 4.5 \mu \mathrm{g} \mathrm{kg}-1$ at the end of the second drying phase and $110.5 \pm 0.6 \mu \mathrm{g} \mathrm{kg}^{-1}$ at the end of seasoning phase) in the SSDCH produced without the addition of the protective cultures. Additionally, in situ the best inhibition of $A$. westerdijkiae was obtained using the $\mathrm{Dh} / \mathrm{Lb}$ inoculum. Indeed, in the FPLs individually inoculated with the bioprotective strains, A. westerdijkiae grew and produced OTA at a higher level than the limit proposed by the Italian Ministry of Health $\left(1 \mu \mathrm{g} \mathrm{kg}^{-1}\right.$, Circolare Ministero Sanità No. 30 10-09/06/1999). OTA production was detected in the meat in the area where A. westerdijkiae grew, producing a yellow slime that covered the entire meat portion of the FPLs, but no growth was observed on the skin. The inoculation of the bioprotective strains either separately or in combination, with A. westerdijkiae reduced or did not permit its growth on the FPLs. Therefore, the dominance of the bioprotective strains was the primary parameter involved in the elimination of 
A. westerdijkiae growth and consequently the elimination of the OTA presence and production. Indeed, at the end of the seasoning phase, the amount of OTA present was less than the limit proposed by the Italian Ministry of Health (Circolare Ministero Sanità No. 30 10-09/06/1999). In a previous study [1], $D$. hansenii was shown to inhibit $A$. ochraceus or P. nordicum in speck and, consequently, eliminated the presence of OTA. Furthermore, several studies [29-31] have demonstrated that inoculated and native $D$. hansenii, $C$. zeylanoides and $H$. burtonii were able to dominate $A$. ochraceus and OTA-producing molds, showing the occurrence of an antagonistic variability at the level of the tested strains. However, $D$. hasenii DIAL 1 produced better inhibition versus the OTA producer A. ochraceus in speck [1] than that observed versus $A$. westerdijkiae in SSDCH. Regarding the decreased activity of $D$. hansenii DIAL1 against $A$. westerdijkiae, it should be noted that the latter strain is more adapted to temperate climates, exhibiting abundant growth at $22{ }^{\circ} \mathrm{C}$, and it typically produces OTA in higher amounts and more consistently than $A$. ochraceus [36,59]. However, although the Aw value typically has a significant effect on OTA levels, decreasing the Aw did not increase the concentration of OTA produced by A. westerdijkiae in the SSDCH model system, since OTA biosynthesis is naturally activated under sub-optimal, weak stress conditions such as 3\%-5\% $\mathrm{NaCl}$ [60]. Therefore, it was necessary to select the strain with the highest antagonistic effect among the isolated species. This finding was confirmed in this study and in a previous study [1]. The significant reduction of OTA appeared to be related to the inhibition of $A$. westerdijkiae growth by the co-inoculated yeasts and LAB. No other hypotheses could be formulated, despite the observation that environmental conditions have different effects on $A$. westerdijkiae OTA production and growth in a sterile dry-cured ham-based medium and that OTA production does not correlate with growth [61]. Furthermore, no mold hyphae were observed on the surfaces of the co-inoculated SSDCH model system and in SSDCH under a stereomicroscope. Consequently, the possibility that the great reduction in OTA levels in the samples treated with a combination of both bioprotective starters may be due to mycotoxin degradation by the yeasts into less toxic compounds was also excluded [1,29,30]. Again, the possibility that OTA could be adsorbed on the yeast cell wall was excluded, despite this activity having been shown for $S$. cerevisiae and $D$. hansenii $[62,63]$. Although the mechanisms by which the mixed bioprotective strains reduce OTA levels need to be elucidated $[29,64]$, the stereoscope observations demonstrated that the reduced OTA levels in the SSDCH model system and SSDCH samples was strictly due to the dominating effect of the mixed bioprotective strains over the OTA-producing A. westerdijkiae.

Despite the antagonistic effect observed in the SSDCH model system at all of the Aw levels tested, it is reasonable to propose that the starter culture should be inoculated before the first drying phase, when the Aw is $0.95 \pm 0.01$ and $A$. westerdijkiae has not started to grow. The suggested concentration of the mixed inoculum should be $10^{6} \mathrm{CFU} \mathrm{cm} \mathrm{cm}^{-2}$ to absolutely ensure that the inoculum can predominate over the A. westerdijkiae. The results suggested that adding this concentration of the mixed starter at the specific production steps confirms the results of different studies [1,13,18,29-32] in which the addition of the starter at the beginning of the production process was suggested for dry-cured hams, when the Aw of the product is still high (0.94-0.95) and can support OTA-producing mold growth. In our study, the mixed starter culture grew rapidly on the SSDCH at this Aw value and blocked the growth of OTA-producing A. westerdijkiae. Therefore, the biopreservative effect of the tested strains was obvious. Consequently, the combination of both strains may be proposed as antagonistic agents to prevent the presence of OTA-producing molds and the bioaccumulation of OTA during SSDCH production (Figure 1).

Finally, as suggested in a previous study [1] for speck production, the application of bioprotective using an adequate hygienic system based on hazard analysis and critical control points (HACCP) can absolutely prevent the presence of OTA in SSDCH. The HACCP system can reduce the level of OTA-producing mold contamination on FBCs and SSDCH and flavor the antagonistic effect of the bioprotective starter [1]. Additionally, the raw material, temperature, and R.H. of the drying and seasoning rooms should be controlled [57]. 


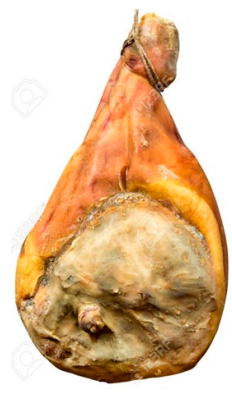

(a)

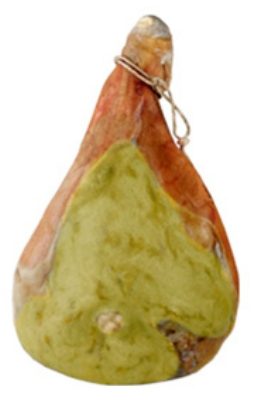

(b)

Figure 1. Short-seasoned dry-cured ham (SSDCH) (a) without; (b) with A. westerdijkiae.

The sensorial acceptability of all the SSDCHs, either inoculated or uninoculated with the bioprotective starter, was confirmed by a triangular test using a panel of 20 non-professional assessors. These assessors did not observe any difference between lots A, B, and C (with bioprotective cultures) and lot D (uninoculated control).

\section{Conclusions}

D. hansenii and L. buchneri are potential biopreservative agents for use in eliminating the growth of the OTA producer $A$. westerdijkiae in SSDCH, a recent Italian dry-cured ham product. The use of selected D. hansenii DIAL1 and L. buchneri Lb4 starter cultures, the control of raw meat and the technological (temperature and R.H.) and hygienic parameters are fundamental for the reduction of health hazards due to the growth of the OTA producer A. westerdijkiae in SSDCH. Consequently, the inoculation of $D$. hansenii or L. buchneri as mixed starter culture strains after the first drying stage could improve the safety and quality of SSDCH.

Author Contributions: All authors contributed equally to the planning, the testing, reporting findings and discussion of the work. All authors have read and agreed to the published version of the manuscript.

Funding: This research did not receive any specific grant from funding agencies in the public, commercial, or not-for-profit sectors.

Conflicts of Interest: None of the authors of this paper has a financial or personal relationship with other people or organizations that could inappropriately influence or bias the content of the paper.

\section{References}

1. Iacumin, L.; Manzano, M.; Andyanto, D.; Comi, G. Biocontrol of ochratoxigenic moulds (Aspergillus ochraceus and Penicillium nordicum) by Debaryomyces hansenii and Saccharomycopsis fibuligera during speck production. Food Microbiol. 2017, 62, 188-195. [CrossRef] [PubMed]

2. Toldrá, F. Proteolysis and lipolysis in flavour development of dry cured meat products. Meat Sci. 1998, 49, 101-110. [CrossRef]

3. Núñez, F.; Rodríguez, M.M.; Bermudez, M.E.; Córdoba, J.J.; Asensio, M.A. Composition and toxigenic potential of the mould population on dry-cured Iberian ham. Int. J. Food Microbiol. 1996, 32, 185-187. [CrossRef]

4. Comi, G.; Orlic, S.; Redzepovic, S.; Urso, R.; Iacumin, L. Moulds isolated from Istrian dried ham at the pre-seasoning and seasoning level. Int. J. Food Microbiol. 2004, 96, 29-34. [CrossRef] [PubMed]

5. Spotti, E.; Berni, E.; Cacchioli, C. Characteristics and application of moulds. In Meat Biotechnology; Toldrà, F., Ed.; Springer Science \& Business Media: New York, NY, USA, 2008; pp. 181-195.

6. Sunesen, L.O.; Stahnke, L.H. Mould starter cultures for dry sausages-selection, application and effects. Meat Sci. 2003, 65, 935-948. [CrossRef]

7. Rojas, F.I.; Jodral, M.; Gosalvez, F.; Pozo, R. Mycoflora and toxigenic Aspergillus flavus in Spanish dry-cured ham. Int. J. Food Microbiol. 1991, 13, 249-256. [CrossRef]

8. Dragoni, I.; Marino, C.; Cantoni, C. Muffe in prodotti carnei salati e stagionati (bresaole e prosciutti crudi). Ind. Alim. 1980, 19, 405-407. 
9. Huerta, T.; Sanchis, V.; Hernandez, J.; Hernandez, E. Mycoflora of dry-salted Spanish ham. Microbiol. Aliment. Nutr. 1987, 5, 247-252.

10. Spotti, E.; Mutti, P.; Campanini, M. Presenza di muffe sui prosciutti durante la prestagionatura e la stagionatura: Contaminazione degli ambienti e sviluppo sulla porzione muscolare. Ind. Cons. 1989, 64, 110-113.

11. Battilani, P.; Pietri, V.A.; Giorni, P.; Formenti, S.; Bertuzzi, T.; Toscani, T.; Virgili, R.; Kozakiewicz, Z. Penicillium populations in dry-cured ham manufacturing plants. J. Food Protect. 2007, 70, 975-980. [CrossRef]

12. Battilani, P.; Formenti, S.; Toscani, T.; Virgili, R. Influence of abiotic parameters on ochratoxin A production by a P. nordicum strain in dry-cured meat model system. Food Contr. 2010, 21, 1379-1744. [CrossRef]

13. Iacumin, L.; Milesi, S.; Pirani, S.; Comi, G.; Chiesa, L.M. Ochratoxigenic moulds and Ochratoxin A in Sausages from Different Areas in Northern Italy: Occurrence, Elimination or Prevention with ozonated air. J. Food Saf. 2011, 31, 538-545. [CrossRef]

14. Comi, G.; Iacumin, L. Ecology of moulds during the pre-seasoning and seasoning of San Daniele dry cured ham. Food Res. Int. 2013, 54, 1113-1119. [CrossRef]

15. Zadravec, M.; Vahčić, N.; Brnic, D.; Markov, K.; Frece, J.; Beck, R.; Lešić, T.; Pleadin, J. A study of surface moulds and mycotoxins in Croatian traditional dry-cured meat products. Int. J. Food Microbiol. 2020, 317, 1-7. [CrossRef]

16. Comi, G.; Manzano, M.; Brichese, R.; Iacumin, L. New case of spoilage in San Daniele Dry Cured Hams. J. Food Saf. 2014, 34, 263-269. [CrossRef]

17. Matrella, R.; Monaci, L.; Milillo, M.A.; Palmisano, F.; Tantillo, M.G. Ochratoxin A determination in paired kidneys and muscle samples from swines slaughtered in southern Italy. Food Contr. 2006, 17, 114-117. [CrossRef]

18. Meftah, S.; Abid, S.; Dias, T.; Rodrigues, P. Mechanisms underlying the effect of commercial starter cultures and a native yeast on ochratoxin A production in meat products. LWT Food Sci. Technol. 2019, 117, 1-7. [CrossRef]

19. Pietri, A.; Bertuzzi, T.; Gualla, A.; Piva, G. Occurrence of Ochratoxin A in raw ham muscles and in pork products from Northern Italy. Int. J. Food Sci. 2006, 18, 99-106.

20. Parussolo, G.; Oliveira, M.S.; Valle Garcia, M.; Olivier Bernardi, A.; Lemos, J.C.; Stefanello, A.; Mallmann, C.A.; Venturini Copetti, M. Ochratoxin A production by Aspergillus westerdijkiae in Italian-type salami. Food Microbiol. 2019, 83, 134-140. [CrossRef]

21. Gil-Serna, J.; Patinño, B.; Cortes, L.; Gonzalez-Jaen, M.T.; Vazquez, C. Aspergillus steynii and Aspergillus westerdijkiae as potential risk of OTA contamination in food products in warm climates. Food Microbiol. 2014, 46, 168-175. [CrossRef]

22. Malir, F.; Ostry, V.; Pfohl-Leszkowicz, A.; Malir, J.; Toman, J. Ochratoxin A: 50 years of researches. Toxins 2016, 8, 191. [CrossRef] [PubMed]

23. Frisvad, J.C.; Frank, M.J.; Houbraken, J.A.M.P.; Kuijpers, A.F.A.; Samson, R.A. New ochratoxin producing species in Aspergillus section Circumdati. Stud. Mycol. 2004, 50, $23-43$.

24. IARC; Ochratoxin, A. Some Naturally Occurring Substances: Food Items and Constituents, Heterocyclic Aromatic Amines and Mycotoxins. In IARC Monograph on the Evolution of Carcinogenic Risks to Humans. International Agency for Research on Cancer; IARC: Geneva, Switzerland, 1993; Volume 56, pp. 489-521.

25. EFSA Panel on Biological Hazards (BIOHAZ). Scientific opinion on the maintenance of the list of QPS biological agents intentionally added to food and feed (2012 up- date). EFSA J. 2012, 10, 3020.

26. Comi, G.; Iacumin, L. The use of bioprotective cultures. In Strategies for Obtaining Healthier Foods; Carballo, J., Lorenzo, J.M., Eds.; Nova Science Publishers, Inc.: New York, NY, USA, 2017; pp. 89-128.

27. Boudra, H.; Le Bars, P.; Le Bars, J. Thermostability of ochratoxin A in wheat under two moisture conditions. Appl. Environ. Microbiol. 1995, 61, 1156-1158. [CrossRef]

28. Rodríguez, A.; Capela, D.; Medina, Á.; Córdoba, J.J. Magan, N. Relationship between ecophysiological factors, growth and ochratoxin A contamination of dry-cured sausage based matrices. Int. J. Food Microbiol. 2015, 194, 71-77. [CrossRef]

29. Andrade, M.J.; Thorsen, L.; Rodriguez, A.; Cordoba, J.J.; Jespersen, L. Inhibition of ochratoxigenic moulds by Debaryomyces hansenii strains for biopreservation of dry-cured meat products. Int. J. Food Microbiol. 2014, 170, 70-77. [CrossRef] 
30. Simoncini, N.; Virgili, R.; Spadola, G.; Battilani, P. Autochthonous yeasts as potential biocontrol agents in dry-cured meat products. Food Contr. 2014, 46, 160-167. [CrossRef]

31. Virgili, R.; Simoncini, N.; Toscani, T.; Leggieri, M.C.; Formenti, S.; Battilani, P. Biocontrol of Penicillium nordicum growth and Ochratoxin A production by Native Yeasts of Dry Cured Ham. Toxins 2012, 4, 68-82. [CrossRef]

32. Peromingo, B.; Núñez, F.; Rodríguez, A.; Alía, A.; Andrade, M.J. Potential of yeasts isolated from dry-cured ham to control ochratoxin A production in meat models. Int. J. Food Microbiol. 2018, 268, 73-80. [CrossRef]

33. Comi, G.; Cantoni, C. I lieviti di insaccati crudi stagionati. Ind. Alim. 1980, 19, 857-860.

34. Asefa, D.T.; Kure, C.F.; Gjerde, R.O.; Omer, M.K.; Langrud, S.; Nesbakken, T.; Skarar, I. Fungal growth pattern, sources and factors of mould contamination in a dry-cured meat production facility. Int. J. Food Microbiol. 2010, 140, 131-135. [CrossRef] [PubMed]

35. Simoncini, N.; Rotelli, D.; Virgili, R.; Quintavalla, S. Dynamics and characterization of yeasts during seasoning of typical Italian dry-cured ham. Food Microbiol. 2007, 24, 577-584. [CrossRef]

36. Meftah, S.; Abid, S.; Dias, T.; Rodrigues, P. Effect of dry-sausage starter culture and endogenous yeasts on Aspergillus westerdijkiae and Penicillium nordicum growth and OTA production. Leb. Wiss. Technol. Food Sci. Technol. 2018, 87, 250-258. [CrossRef]

37. Chi, Z.; Chi, Z.; Liu, G.; Wang, F.; Ju, L.; Zhang, T. Saccharomycopsis fibuligera and its applications in biotechnology. Biotech. Adv. 2009, 27, 423-431. [CrossRef] [PubMed]

38. Hammes, W.P.; Knauf, H.J. Starters in the processing of meat products. Meat Sci. 1994, 36, 155-168. [CrossRef]

39. Björnberg, A.; Schnürer, J. Inhibition of the growth of the grain-storage moulds in vitro by the yeast Pichia anomala (Hansen) Kurtzman. Can. J. Microbiol. 1993, 39, 623-628. [CrossRef]

40. Spotti, E.; Berni, E.; Cacchioli, C.; Simoncini, N.; Quintavalla, S. Growth and antagonistic activity of Hyphopichia burtonii against other fungal species frequently found on meat products during maturation. Ind. Cons. 2009, 84, 11-22.

41. Bleve, G.; Grieco, F.; Cozzi, G.; Logrieco, A.; Visconti, A. Isolation of epiphytic yeasts with potential for biocontrol of Aspergillus carbonarius and A. niger on grape. Int. J. Food Microbiol. 2006, 108, 204-209. [CrossRef]

42. Lima, G.; Arru, S.; De Curtis, F.; Arras, G. Influence of antagonistic, host fruit and pathogen on the biological control of postharvest fungal diseases by yeasts. J. Ind. Microbiol. Biotechnol. 1999, 23, 223-229. [CrossRef]

43. Multon, J.L.; Bizot, H. Water adsorption in cereal foods and water activity measurement. In Cereals for Food and Beverages; Ingletti, G.E., Munck, L., Eds.; Academic Press: New York, NY, USA, 1980; pp. 97-119.

44. Cocolin, L.; Urso, R.; Rantsiou, K.; Cantoni, C.; Comi, G. Dynamics and characterization of yeasts during natural fermentation of Italian sausages. FEMS Yeast Res. 2006, 6, 692-701. [CrossRef]

45. Andrade, M.J.; Rodriguez, A.; Casado, E.M.; Bermùdez, E.; Cordoba, J.J. Differentiation of yeasts growing on dry-cured meat Iberian ham by mitochondrial DNA restriction analysis, RAPD-PCR and their volatile compounds production. Food Microbiol. 2009, 26, 578-586. [CrossRef] [PubMed]

46. Dall'Asta, C.; Galaverna, G.; Bertuzzi, T.; Moseriti, A.; Pietri, A.; Dossena, A.; Marchelli, R. Occurrence of ochratoxin A in raw ham muscle, salami and dry-cured ham from pigs fed with contaminated diet. Food Chem. 2010, 120, 978-983. [CrossRef]

47. Rodríguez, A.; Rodríguez, M.; Martín, A.; Delgado, J.; Córdoba, J.J. Presence of ochratoxin A on the surface of dry-cured Iberian ham after initial fungal growth in the drying stage. Meat Sci. 2012, 92, 728-734. [CrossRef] [PubMed]

48. Comi, G.; Chiesa, L.; Panseri, S.; Orlic, S.; Iacumin, L. Evaluation of different methods to prevent Penicillium nordicum growth and Ochratoxin A (OTA) presence on country-style sausages. World Mycotoxin J. 2013, 6, 411-418. [CrossRef]

49. Masih, E.I.; Paul, B. Secretion of beta-1,3-glucanases by the yeast Pichia membranifaciens and its possible role in the biocontrol of Botrytis cinerea causing grey mold disease of the grapevine. Curr. Microbiol. 2002, 44, 391-395. [CrossRef]

50. Masoud, W.; Poll, L.; Jakobsen, M. Influence of volatile compounds produced by yeasts predominant during processing of Coffea arabica in East Africa on growth and ochratoxin A (OTA) production by Aspergillus ochraceus. Yeast 2005, 22, 1133-1142. [CrossRef] [PubMed]

51. Taczman-Brückner, A.; Mohácsi-Farkas, C.; Balla, C.; Kiskó, G. Mode of action of Kluyveromyces lactis in biocontrol of Penicillium expansum. Acta Alim. Hung. 2005, 34, 153-160. [CrossRef] 
52. Fialho, M.B.; Toffano, L.; Pedroso, M.P.; Augusto, F.; Pascholati, S.F. Volatile organic compounds produced by Saccharomyces cerevisiae inhibit the in vitro development of Guignardia citricarpa, the causal agent of citrus black spot. World J. Microbiol. Biotechnol. 2009, 2, 925-932. [CrossRef]

53. Hernández-Montiel, L.G.; Ochoa, J.L.; Troyo-Diéguez, E.; Larralde-Corona, C.P. Biocontrol of postharvest blue mould (Penicillium italicum Wehmer) on Mexican lime by marine and citrus Debaryomyces hansenii isolates. Postharvest Biol. Technol. 2010, 56, 181-187. [CrossRef]

54. Abrunhosa, L.; Rodrigues, A.I.; Guimaraes, A.; Pereira, V.L.; Parpot, P.; Mendes-Faia, A.; Venâncio, A. Biodegradation of ochratoxin A in Pediococcus parvulus isolated from Douro wines. Int. J. Food Microbiol. 2014, 188, 45-52. [CrossRef]

55. Pereira, M.; Beux, M.; Pagnoncelli, B.; Soccol, V.T.; Rodrigues, C.; Soccol, C.R. Isolation, selection, and evaluation of antagonistic yeast and lactic acid bacteria against ochratoxigenic fungus $A$ westerdijkiae on coffe beans. Lett. Appl. Microbiol. 2016, 62, 96-101. [CrossRef]

56. Marquina, D.; Barroso, J.; Santos, A.; Peinado, J.M. Production and characteristics of Debaryomyces hansenii killer toxin. Microbiol. Res. 2001, 156, 387-391. [CrossRef] [PubMed]

57. Zhao, Y.; Tu, K.; Shao, X.F.; Jing, W.; Su, Z.P. Effects of the yeast Pichia guilliermondii against Rhizopus nigricans on tomato fruit. Postharvest Biol. Technol. 2008, 49, 113-120. [CrossRef]

58. Sánchez-Montero, L.; Córdoba, L.J.J.; Peromingo, B.; Álvarez, M.; Núñez, F. Effects of environmental conditions and substrate on growth and ochratoxin a production by Penicillium verrucosum and Penicillium nordicum: Relative risk assessment of OTA in dry-cured meat products. Food Res. Int. 2019, 12, 604-611. [CrossRef] [PubMed]

59. Xu, X.M.; Monger, W.; Ritieni, A.; Nicholson, P. Effect of temperature and duration of wetness during initial periods on disease development, fungal biomass and mycotoxin concentrations on wheat inoculated with single, or combinations of Fusarium species. Plant Path. 2007, 56, 943-956. [CrossRef]

60. Samson, R.A.; Hong, S.B.; Frisvad, J.C. Old and new concepts of species differentiation in Aspergillus. Med. Mycol. 2006, 44, 133-148. [CrossRef] [PubMed]

61. Schmidt-Heydt, M.; Richter, W.; Michulec, M.; Buttinger, G.; Geisen, R. Comprehensive molecular system to study the presence, growth and ochratoxin A biosynthesis of Penicillium verrucosum in wheat. Food Addit. Contam. 2008, 25, 989-996. [CrossRef]

62. Vipotnik, Z.; Rodríguez, A.; Rodrigues, P. Aspergillus westerdijkiae as a major ochratoxin A risk in dry-cured ham based-media. Int. J. Food Microbiol. 2017, 241, 244-251. [CrossRef]

63. Gil-Serna, J.; Vázquez, C.; Sardiñas, N.; González-Jaén, M.T.; Patiño, B. Revision of ochratoxin A production capacity by the main species of Aspergillus section Circumdati. Aspergillus steynii revealed as the main risk of OTA contamination. Food Contr. 2011, 22, 343-345.

64. Shetty, P.H.; Hald, B.; Jespersen, L. Surface binding of aflatoxin B1 by Saccharomyces cerevisiae strains with potential decontaminating abilities in indigenous fermented foods. Int. J. Food Microbiol. 2007, 113, 41-46. [CrossRef]

Publisher's Note: MDPI stays neutral with regard to jurisdictional claims in published maps and institutional affiliations.

(C) 2020 by the authors. Licensee MDPI, Basel, Switzerland. This article is an open access article distributed under the terms and conditions of the Creative Commons Attribution (CC BY) license (http://creativecommons.org/licenses/by/4.0/). 